\title{
The Effect of Entry Regulation on Process Innovation in the Swiss Mail Industry
}

\author{
Helmut M. Dietla ${ }^{a}$, Andreas Grütter ${ }^{\text {b }}$, Martin Lutzenberger ${ }^{c}$, \\ Cátia Felisberto ${ }^{\text {d }}$ and Matthias Finger ${ }^{\mathrm{e}}$
}

JEL-Classification: L51, L87

Keywords: end-to-end competition, entry regulation, mail industry, process innovation, worksharing

\section{Introduction}

The mail industry, like other network industries such as the electricity and telecommunications industries, is currently undergoing fundamental changes. In particular, now that both the European Union's as well as Switzerland's parcel markets are largely deregulated, authorities are determined to open the letter markets to competitors, anticipating that competitive pressure induces competitors to become more efficient by way of innovation. In this paper, we ask whether competitive pressure in the Swiss mail industry will actually lead to more incentives to innovate or not.

There is a consensus among the industrialized countries that some further deregulation is desirable. However, there is no consensus as to how far this process should go. Supporters of a full deregulation (end-to-end competition) promote a scenario where new competitors are fully independent of the incumbent postal operator and collect, sort, transport, and deliver their mail themselves. However,

a Prof. Dr. Helmut M. Dietl, University of Zurich, Institute of Strategy and Business Economics, Services and Operations Management, Universitätsstrasse 84, CH-8006 Zurich. Phone: +41 4463453 12, Fax: +41 4463453 01, E-Mail: helmut.dietl@isu.uzh.ch.

b lic. oec. publ. Andreas Grütter, University of Zurich, Institute of Strategy and Business Economics, Services and Operations Management.

c Dipl. Volkswirt Martin Lutzenberger, University of Zurich, Institute of Strategy and Business Economics, Services and Operations Management.

d MScE Cátia Felisberto, EPF Lausanne, College of Management and Technology, Management of Network Industries.

e Prof. Dr. Matthias Finger, EPF Lausanne, College of Management and Technology, Management of Network Industries. 
there is also another view, chiefly supported by the United States. Supporters of this view argue that the high costs of establishing and maintaining an area-wide delivery network are to a large extent fixed costs, hence delivery exhibits strong economies of scale (see Rogerson and Takis, 1993; Cazals, De Rycke, FloRens and Rouzard, 1997; Postal Rate Commission, 2000). Economies of scale in delivery can best be realized if there is only a single provider delivering mail. None of the other main activities of the postal value chain exhibit particularly strong economies of scale. ${ }^{1}$ Thus, competition is encouraged in the "upstream" segment (collection, sorting, and transportation) and discouraged in the "downstream” segment (delivery). To facilitate this scenario (known as worksharing), the incumbent postal operator is given the exclusive right to deliver its mail, but is forced to allow competitors access to its delivery network.

In addition to end-to-end competition and worksharing, there is a third scenario, which results from a combination of these two scenarios. In this new scenario (known as worksharing with bypass), entrants can choose to either compete with the incumbent end-to-end, to make use of the incumbent's obligation to deliver the entrants' mail, or both. The last option gives entrants the opportunity for a highly selective market entry, delivering only some types of mail (e.g. mail to cities) and relying on the incumbent to deliver the remaining mail (e.g. mail to remote areas).

The federal council of Switzerland has not yet decided to pursue deregulation towards any particular state, although the council is committed to a gradual market opening (Federal Council, 2002). ${ }^{2}$ In light of this situation, the principal issue from an economic point of view becomes how to best proceed with the deregulation of the letter market. In particular, given the options outlined so far, the question is whether to steer the mail market towards a state of end-toend competition, a state of worksharing without bypass, or a state of worksharing with bypass.

We give a brief overview of how postal economists have approached this question so far. Crew and KLeindorfer (1998) begin with a general analysis of the nature and justification of the universal service obligation (USO), and then

1 In addition to the empirical literature referenced above, see also Bradley, Colvin and Panzar (1997) for its discussion of how the possibility of outsourcing helps with the interpretation of some empirical findings.

2 As of April 1, 2006, the Swiss government lowered the weight for letters reserved exclusively to the incumbent to at most 100 grams (Postverordnung, 2006). By comparison, the weight limit for members of the European Union is set at 50 grams as of January 1, 2006, although individual members are free to lower this limit even further. 
develop an analytical framework to determine the optimal scope of the reserved area. ${ }^{3}$ Different in its aim, Cremer, Grimaud, Florens, Marcy, Roy and Toledano (2001) focus on the question of what strategies the incumbent is likely to adopt in the face of the threat of entry, and on what their consequences are. PANZAR (2002) critically reviews the assumptions underlying the idea of mandating access to the incumbent postal operator's downstream network. He argues that mandating access to the incumbent's delivery network (i.e. worksharing) is best seen as a temporary instrument to promote competition and illustrates how worksharing can lead to inefficiencies in the long run.

All of these studies bypass the question of whether competition leads to more innovation, which in turn leads to more efficient processes and lower prices. They calculate the new prices directly based on the competitive situation in the enduser market. They neglect the question that competitors have different incentives to improve efficiency based on the new competitive situation. In this paper, we try to fill this gap with regards to the Swiss mail industry.

There is of course literature that deals with the question of competition and innovation in a general setting. In his seminal work, ARROw (1962) studies cost reducing innovations and concludes that "the incentive to invest [in R\&D] is less under monopolistic than under competitive conditions". Arrow looks at the incentive of an outside investor who can sell his innovation to the firms in the product market on a royalty basis. The firms in the product market can then either produce at their old costs, or pay royalties to the investor and produce at reduced marginal costs. We do not believe that Arrow's setting is appropriate to answer the question we are interested in. We want to know how the new competitive setting affects the national economy. Thus, we are primarily interested in how the postal operators' incentives to innovate are affected by the new competitive setting. We are not as much interested in how the incentives change for a third party supplier. For this reason, in this paper's model, there is no outside investor. Instead, market participants invest into innovations only they can benefit from. This is an important difference to Arrow's model which means that Arrow's conclusion does not necessarily hold for our setting as well.

Instead of going into more detail, we recommend Martin (1993) and Boone (2000), who have already done expert overviews of the existing literature on competition and innovation. We also mention Baily and Gersbach (1995), Blundell, Griffith and Van Reenen (1995) and Nickell (1996) for their empirical work on competition and innovation.

3 The reserved area describes the services only the established postal operator is allowed to provide. Its main purpose is to finance the costs of the universal service obligation. 
This paper is organized as follows. In Section 2, we introduce our model. The model takes into account the two most important characteristics of the mail industry: Economies of scale in delivery and the universal service obligation. In Section 3, we calibrate our model. We choose to work with calibration rather than to design a model producing easily interpretable analytical results. This approach allows us to work with a much more accurate model of postal economics, containing features that would otherwise have to be sacrificed for simplicity: It allows us to work with two separate regions with different costs, two different segments of the postal value chain, and different costs for the incumbent and entrant. In Section 4, we present the results. We find that in general, a profitmaximizing monopolist has strong incentives to invest in process innovations. However, the monopolist's behaviour does not translate into added benefits for the consumers. Unless the entrant can innovate at no more than about a third of the incumbents' costs, the positive effects of process innovation on welfare decrease with liberalization. Section 5 concludes.

\section{The Model}

We introduce our model by developing the assumptions for the reference case, i.e. the regulated monopoly. ${ }^{4}$ Then, we consider the three types of entry regulation outlined in the introduction: end-to-end competition, worksharing without bypass, and worksharing with bypass.

\subsection{Reference Case: Regulated Monopoly}

We assume that a customer's (or sender's) utility depends on the quantity of letters sent. Our representative sender has quasilinear preferences in money and a quadratic utility function over quantities. We divide the market into two regions $r=h, l$, where $h$ denotes the urban region with high population and $l$ denotes the rural region with low population. The utility function of the representative sender is defined by:

$$
U=\sum_{r}\left(a^{r} q^{r}-\frac{1}{2} b^{r}\left(q^{r}\right)^{2}\right)+y
$$

4 As noted in the introduction, Swiss Post only enjoys monopoly protection up to a weight limit of 100 grams. However, the present state is still a de facto monopoly, since only about $11 \%$ of all letters fall outside of the reserved area (PostReg, 2005, p. 12). 
where $a, b>0$. Variables $q^{b}$ and $q^{l}$ refer to the amount of mail sent to each region, and $y$ is the amount of money spent on other goods.

The sender must satisfy the budget constraint $y+p \sum_{r} q^{r} \leq m$, where $p$ denotes the monopolist's price. The monopolist's price is uniform across all regions. Prices are subject to approval by the regulatory authorities. In determining whether a price is approved or not, the price level of the newly proposed basket of services is compared with the price level of the same services at past prices. Current price levels are raised in order to account for the effects of inflation, and lowered in order to account for gains in productivity. For a more in depth explanation of the ways to determine and implement pricing schemes, we refer to De Villemeur, Cremer, Roy and Toledano (2003). Thus, in principle, gains in productivity induced by lower costs lead to lower prices. This relation raises an important question, namely the question of whether a monopolist still has actually any incentives for cost savings if the monopolist must lower prices in accordance with the observed decrease in costs. We argue that incentives for cost savings remain even for a monopolist. The principal reason is that while prices are corrected in order to account for gains in productivity in the long run, the monopolist is allowed to keep the added profits from innovation in the short run, i.e. between dates where price levels are determined. In the short run, the monopolist behaves as if price levels remained constant. For this reason, in our model, we treat the monopolist's price level as an exogenously given constant. Completing the description of the budget constraint, parameter $m$ denotes the initial wealth endowment.

Utility maximization then leads to the demand function for region $r$ :

$$
q^{r}(p)=\frac{1}{b^{r}}\left(a^{r}-p\right)
$$

We divide the postal value chain into two segments $s=u, d$. We regard the activities of collection, transportation, and sorting as a composite upstream activity, which we denote by $u$. We denote delivery, the downstream activity, by $d$. The upstream activities come at a marginal cost of $c_{u}^{r}$. The universal service obligation (USO) requires the monopolist to maintain its delivery network regardless of market demand. Therefore, a part of the monopolist's downstream costs is fixed. We denote these fixed costs by $F_{d}$, and the variable downstream costs by $c_{d}^{r}$.

Process innovations can occur in the upstream and the downstream activities. More efficient letter sorting machines are an example of upstream innovations. Optimized delivery routes are an example of downstream innovations. We introduce process innovations into our model by assuming that the regulated 
monopolist can reduce its initial marginal costs by a fraction $k_{s}^{r}$. Following D'Aspremont and JaCQuemin (1988) we assume that the investments in cost reduction are a quadratic function of the cost reduction:

$$
I_{s}^{r}=\frac{1}{2} z\left(k_{s}^{r}\right)^{2}
$$

Parameter $z$ is a scale parameter, with $z>0$. Profit is given by the function:

$$
\Pi=\sum_{r}\left[\left(p-\sum_{s}\left(1-k_{s}^{r}\right) c_{s}^{r}\right) q^{r}-\sum_{s} I_{s}^{r}\right]-F_{d}
$$

Given the uniform price, the monopolist chooses the profit-maximizing cost reductions $k_{s}^{r}$. We obtain the equilibrium value:

$$
k_{s}^{r}=\frac{\left(q_{s}^{r} c_{s}^{r}\right)}{z}
$$

\subsection{Multiple Service Providers}

We now add the possibility of market entry. When designing a model of market entry, one must ask whether to model entry by one potential entrant or by several entrants. If several entrants are considered, then new entrants enter as long as market entry remains profitable. With every additional entrant, each entrant's profit decreases. The last entrant to enter is the one who is just indifferent between entering and staying out of the market. This indifference is equivalent to the condition that each entrant's profit must be zero. In this case, we can say that entrants behave like a competitive fringe, which is equivalent to a situation where there is just one entrant who earns a profit of zero. If one assumes only one entrant, then it is possible for the entrant to earn a strictly positive profit. We are interested not only in the effects of entry regulation on the incumbent service provider, but also in the effects of entry regulation on the entrant. We believe that it is more plausible to assume that entrants can indeed make a profit when discussing this paper's specific question. For this reason, we chose to abstain from the assumption of a competitive fringe and instead model just one entrant, who is allowed to earn a strictly positive profit.

This entrant $E$ can enter either one or both regions, and choose different prices $p_{E}^{r}$ for each region. Thus, the entrant's prices are endogenous variables. 
On the other hand, the incumbent $I$ must serve both regions at an exogenously given uniform price $p_{I}$.

The customers' utility function is

$$
U=\sum_{r}\left(a_{I}^{r} q_{I}^{r}-\frac{b^{r}}{2}\left(q_{I}^{r}\right)^{2}+a_{E}^{r} q_{E}^{r}-\frac{b^{r}}{2}\left(q_{E}^{r}\right)^{2}-e b^{r} q_{I}^{r} q_{E}^{r}\right)+y
$$

where $a, b>0$ and $0<e<1$. The parameter $e$ allows for differentiated products. The restriction imposed on this parameter means that the service providers' products are imperfect substitutes. Given the budget constraint $y+\sum_{r}\left(p_{I} q_{I}^{r}+p_{E}^{r} q_{E}^{r}\right) \leq m$, utility maximization leads to the demand functions:

$$
\begin{aligned}
& q_{I}^{r}\left(p_{I}, p_{E}^{r}\right)=\frac{1}{b^{r}\left(1-e^{2}\right)}\left(a_{I}^{r}-e a_{E}^{r}-p_{I}+e p_{E}^{r}\right) \\
& q_{E}^{r}\left(p_{E}^{r}, p_{I}\right)=\frac{1}{b^{r}\left(1-e^{2}\right)}\left(a_{E}^{r}-e a_{I}^{r}-p_{E}^{r}+e p_{I}\right)
\end{aligned}
$$

As mentioned in the description of the reference case, the USO results in a fixed cost for the incumbent, which we denote by $F_{I d}$. The entrant is not subject to the obligation to maintain its delivery network, and therefore we assume that all of the entrant's costs are variable in the long run. For a discussion of this assumption, see De Donder, Cremer and Rodriguez (2005). The incumbent can reduce its initial marginal costs by a fraction $k_{I s}^{r}$ at investments of

$$
I_{I s}^{r}=\frac{1}{2} z\left(k_{I s}^{r}\right)^{2}
$$

and the entrant can reduce its initial marginal costs by a fraction $k_{E s}^{r}$ at investments of

$$
I_{E s}^{r}=\frac{1}{2} z\left(k_{E s}^{r}\right)^{2}
$$

For simplicity, we first assume that the incumbent's and entrant's scale parameter is the same. Then, we introduce the possibility of different scale parameters. This is done to reflect the idea that due to their greater flexibility, entrants can 
innovate at lower costs than incumbents. We note that firms invest individually. In principle, innovation could be treated as a collective public good where both firms reap the benefits of investment jointly. In order to solve the incentive problem associated with the investment in public goods, firms could make use of contracts. We decide however not to pursue this approach because we were unable to find any evidence competitors in the postal market actually participate in joint $R \& D$ projects. We believe that is more prudent to assume that firms do not cooperate.

\subsubsection{End-to-End Competition}

In the case of end-to-end competition, the entrant competes with the incumbent over the whole value chain. The profit functions are:

$$
\begin{gathered}
\Pi_{I}=\sum_{r}\left[\left(p_{I}-\sum_{s}\left(1-k_{I s}^{r}\right) c_{I s}^{r}\right) q_{I}^{r}-\sum_{s} I_{I s}^{r}\right]-F_{I d} \\
\Pi_{E}=\sum_{r}\left[\left(p_{E}^{r}-\sum_{s}\left(1-k_{E s}^{r}\right) c_{E s}^{r}\right) q_{E}^{r}-\sum_{s} I_{E s}^{r}\right]
\end{gathered}
$$

Given the uniform price $p_{I}$, the incumbent chooses the profit-maximizing cost reductions $k_{I s}^{r}$. Simultaneously, the entrant maximizes for prices $p_{E}^{r}$ and cost reductions $k_{E s}^{r}$. Assuming strictly positive fixed costs in delivery, that there are no fixed costs in the upstream activities, that the rural areas marginal costs are strictly higher than the corresponding costs of the urban area, and that the incumbents price is set such that the incumbent breaks even over the whole market, the entrant does not enter the rural region. The reason is that the entrant cannot set a price in the rural region that it is high enough to cover its marginal costs, yet low enough to be competitive with the incumbent's uniform price.

\subsubsection{Worksharing without Bypass}

In the case of worksharing without bypass, incumbent and entrant compete for upstream activities. The incumbent retains the monopoly on delivery, but is required to deliver the entrant's mail at a uniform access price $\alpha$ per unit of mail. ${ }^{5}$ Profit functions are given by:

5 The access price can either be negotiated or set directly by the regulating authority. For our model, we assume that the access price resembles the incumbent's delivery costs before 


$$
\begin{gathered}
\Pi_{I}=\sum_{r}\left[\left(p_{I}-\sum_{s}\left(1-k_{I s}^{r}\right) c_{I s}^{r}\right) q_{I}^{r}-\sum_{s} I_{I s}^{r}+\sum_{s}\left(\alpha-\left(1-k_{I s}^{r}\right) c_{I s}^{r}\right) q_{E}^{r}\right]-F_{I d} \\
\Pi_{E}=\sum_{r}\left[\left(p_{E}^{r}-\left(\left(1-k_{E u}^{r}\right) c_{E u}^{r}+\alpha\right)\right) q_{E}^{r}\right]-I_{E u}^{r}
\end{gathered}
$$

The term $\sum_{r}\left[\left(p_{I}-\sum_{s}\left(1-k_{I s}^{r}\right) c_{I s}^{r}\right) q_{I}^{r}\right]$ is the profit margin resulting from mail collected, sorted, transported, and delivered by the incumbent. The term $\sum_{r}\left[\sum_{s}\left(\alpha-\left(1-k_{I s}^{r}\right) c_{I s}^{r}\right) q_{E}^{r}\right]$ is the profit margin resulting from delivering the entrant's mail. The entrant's profit function is similar to the entrant's profit function under end-to-end competition. The difference is that the entrant's marginal costs for delivery after cost reduction $\left(1-k_{E d}^{r}\right) c_{E d}^{r}$ are replaced by the access fee $\alpha$. Furthermore, the entrant has no innovation incentives in the downstream segment. Given the incumbent's uniform price $p_{I}$, the incumbent maximizes profit for cost reductions $k_{I s}^{r}$. Simultaneously, the entrant maximizes profit for prices $p_{E}^{r}$ and cost reductions $k_{E u}^{r}$. Depending on whether the prices $p_{E}^{r}$ result in a positive demand for the entrant's services, the entrant enters either one or both regions.

\subsubsection{Worksharing with Bypass}

The case of worksharing with bypass is a combination of the previous cases. The entrant can enter either one or both regions, and either competes with the incumbent over the whole value chain, or provides only the upstream activities and uses the incumbent's delivery network. This choice does not have to be the same in the two regions. The entrant's choice on how to compete depends on how the entrant's marginal costs after reduction by process innovations compare to the access price. If $\alpha>\left(1-k_{E d}^{r}\right) c_{E d}^{r}$ for all $r$, then the profit functions are the same as under end-to-end competition. If $\alpha<\left(1-k_{E d}^{r}\right) c_{E d}^{r}$ for all $r$, then the profit functions are the same as under worksharing without bypass. In the case in which the entrant uses the incumbent's delivery network only in the rural region, i.e., if $\alpha>\left(1-k_{E d}^{h}\right) c_{E d}^{h}$ and $\alpha<\left(1-k_{E d}^{l}\right) c_{E d}^{l}$, profits are:

innovation takes place. This result is a plausible outcome of negotiations between the incumbent and the entrant and a reasonable starting point for a regulating authority. However, access prices determined in this way are not necessarily socially optimal. For the purposes of our model, we take the access price as an exogenous variable. 


$$
\begin{aligned}
\Pi_{I}= & \sum_{r}\left[\left(p_{I}-\sum_{s}\left(1-k_{I s}^{r}\right) c_{I s}^{r}\right) q_{I}^{r}\right] \\
& -\sum_{s} I_{I s}^{r}+\sum_{s}\left(\alpha-\left(1-k_{I s}^{l}\right) c_{I s}^{l}\right) q_{E}^{l}-F_{I d} \\
\Pi_{E}= & \left(p_{E}^{h}-\sum_{s}\left(1-k_{E s}^{h}\right) c_{E s}^{b}\right) q_{E}^{h} \\
& -\sum_{s} I_{E s}^{h}+\left(p_{E}^{l}-\left(1-k_{E u}^{l}\right) c_{E u}^{l}+\alpha\right) q_{E}^{l}-I_{E u}^{l}
\end{aligned}
$$

The term $\sum_{s}\left(\alpha-\left(1-k_{I s}^{l}\right) c_{I s}^{l}\right) q_{E}^{l}$ is the incumbent's profit margin resulting from delivering the entrant's mail to the rural region. The term $\left(p_{E}^{b}-\sum_{s}\left(1-k_{E s}^{b}\right) c_{E s}^{b}\right) q_{E}^{b}$ is the entrant's profit margin resulting from competing end-to-end in the urban region. The term $\left(p_{E}^{l}-\left(1-k_{E u}^{l}\right) c_{E u}^{l}+\alpha\right) q_{E}^{l}$ is the entrant's profit margin resulting from competing in the upstream segment in the rural region. The choice variables are the same as in the previous cases.

In all cases, the optimal cost reductions are proportional to the volume of mail and to the costs of the corresponding region and segment. The result that process innovations are driven mainly by quantities seems straightforward. However, quantities reflect the specifics of the postal market adapted to a certain regulatory scenario, taking into account the competitive environment.

\section{Calibration}

In order to obtain quantitative results, we first calibrate our model for the regulated monopoly, using data of the Swiss letter market. Then, to predict the outcomes for multiple service providers, we modify the parameters accordingly.

In order to calculate the parameters of the demand function for a regulated monopoly, we assume a uniform price equal to $p_{R M}=€ 0.5$, and a corresponding total demand of $q_{R M}=3$ billion. A quarter of the total amount is sent to the rural region, thus $q_{R M}^{h}=2.25$ billion and $q_{R M}^{l}=750$ million. For the price elasticity of demand, we use the estimation $\eta=-0.5 .{ }^{6}$ Using

6 There is some divergence in the literature concerning the price elasticity of demand in the letter market (CAzals and Florens, 2002). The literature claims that $-0.9 \leq \eta \leq-0.2$. Therefore, we performed extensive sensitivity analyses on our results for these values. Our qualitative results are independent of $\eta$ within this range. 


$$
q_{R M}^{r}\left(p_{R M}\right)=\frac{a_{R M}^{r}-p_{R M}}{b_{R M}^{r}}
$$

and

$$
\eta=-\frac{1}{b_{R M}^{r}} \frac{p_{R M}}{q_{R M}^{r}}
$$

we can calculate the parameters determining the demand function of each region. Swiss Post is able to approximately break even in the letter market. Therefore, the monopolist's initial profit $\Pi_{R M}$ is zero. Assuming that the monopolist's uniform price remains unchanged, the monopolist can increase profits through innovation. ${ }^{7}$

Total delivery costs amount for approximately half the total costs, i.e., half the total revenue under the assumption that there is no profit. As outlined in Dietr, Trinkner and Bleisch (2005) we estimate that $60 \%$ of the monopolist's delivery costs are fixed, i.e., $F_{d}=€ 450$ million. We make the assumption that all upstream costs are variable. Although a simplification, this assumption is essentially compatible with the empirical literature. ${ }^{8}$

Given the proportion between marginal costs in the urban and rural regions, as well as the observed prices, quantities, profits, and fixed costs in the reference case, we can derive the marginal costs for each activity. Defining $c_{u}^{l} \equiv 2 c_{u}^{b}$, we obtain $c_{u}^{b}=€ 0.2, c_{u}^{l}=€ 0.4, c_{d}^{b}=€ 0.08$ and $c_{d}^{l}=€ 0.16$. Please note that the marginal cost in the high cost area is twice the marginal cost in the low cost simply by definition. In other words, we differentiate between areas on the sole basis of the magnitude of a region's marginal cost, rather than geographic considerations. Of course, this approach requires a reasonably accurate estimate of the regions' respective proportions. ' Furthermore we assume constant marginal costs. We make this assumption mainly since we do not have any data indicating otherwise, and since it is essentially in line with the empirical literature. ${ }^{10}$

7 If the incumbent's price is regulated in accordance with price-based or cost-based regulation (see Braeutigam and Panzar (1989) for an overview), the regulator reduces the uniform price if profits increase as a result of innovation. Even though this price reduction results in increased consumer surplus, the effect on total welfare is not easily determined as innovation incentives and industry profits decrease. We continue to take the incumbent's price as an exogenous variable, and assume that it remains unchanged.

8 See Rogerson and Takis (1993), Cazals, De Rycke, Florens and Rouzard (1997) and Postal Rate Commission (2000).

9 See Dietl, Trinkner and Bleisch (2005).

10 See Rogerson and Takis (1993), Cazals, De Rycke, Florens and Rouzard (1997) and Postal Rate Commission (2000). 
Assuming that a one percent decrease of marginal costs requires identical investments in all segments and regions, we have to determine a value of the scale parameter $z$. In January 2003, Swiss Post launched a project called Reengineering Mail Processing, i.e., REMA (Sw wss Post, 2003). Swiss Post estimates that the expected cost savings resulting from a restructuring of internal processes in the upstream segment amount to 25 percent. Based on this information, and given that $k_{s}^{r}=q_{s}^{r} c_{s}^{r} / z$, we obtain $z=1.8 \cdot 10^{9}$. As noted before, we start from the assumption that the incumbent and entrant innovate at the same relative costs. Then, we introduce the possibility of a different scale parameter for the entrant.

We set the parameter that determines the degree of product differentiability to be equal to $e=0.75$, which is in line with De Donder, Cremer, Florens, Grimaud and Rodriguez (2001). Furthermore, in case the entrant offers its mail service at the same price as the incumbent, we assume that the incumbent receives a market share of $x=70 \% .{ }^{11}$ Finally, by substituting the incumbent's uniform price $p_{I}$ and the entrant's prices $p_{E}^{r}$ for $p_{R M}$ and using the relation that describes the incumbent's advantage

$$
q_{I}^{r} /\left(q_{I}^{r}+q_{E}^{r}\right)=x
$$

we can solve the demand functions of each region for the given demand parameters $a_{E}^{r}$ and $a_{I}^{r}$, since

$$
a_{I}^{r}=a_{R M}^{r}
$$

and

$$
a_{E}^{r}=\frac{1}{1-e+e / x}\left(a_{I}\left(e-1+\frac{1}{x}\right)+p(1-e)\left(2-\frac{1}{x}\right)\right)
$$

Note that parameters $b_{E}^{r}$ and $b_{I}^{r}$ are derived using equations (17) and (18) in an analogous manner as in the case of regulated monopoly.

11 This value is a weighted average of the values quoted in Dietr, Trinkner and Bleisch (2005). The incumbent's advantage results from switching costs of the consumers. All other things being equal, consumers have no incentive to switch to an alternative service provider who offers the same products at the same quality at the same price. 
The regulator sets the access price to be equal to the incumbent's average costs of delivery per unit. Thus, the regulator divides the observed total downstream costs by the total amount of mail delivered, obtaining

$$
\alpha=\frac{\sum_{r}\left(c_{I d}^{r} q_{I}^{r}\right)+F_{I d}}{\sum_{r} q_{I}^{r}}=€ 0.25
$$

This policy is compatible with the political aim to allow the incumbent postal operator to break even. ${ }^{12}$

\section{Results \& Discussion}

Table 1 shows the investments in innovation by scenario.

Table 1: Investments in Innovation by Scenario (Figures are in Millions of Euros)

\begin{tabular}{|c|c|c|c|c|c|c|c|c|}
\hline \multirow[t]{3}{*}{ Scenario } & \multicolumn{5}{|c|}{ Investments by the Incumbent } & \multicolumn{3}{|c|}{ Investments by the Entrant } \\
\hline & \multicolumn{2}{|c|}{ Urban Area } & \multicolumn{2}{|c|}{ Rural Area } & \multirow{2}{*}{$\begin{array}{l}\text { Total } \\
\text { Incum- } \\
\text { bent }\end{array}$} & \multicolumn{2}{|c|}{ Urban Area } & \multirow[b]{2}{*}{$\begin{array}{c}\text { Total } \\
\text { Entrant }\end{array}$} \\
\hline & $\begin{array}{l}\text { Up- } \\
\text { stream }\end{array}$ & $\begin{array}{l}\text { Down- } \\
\text { stream }\end{array}$ & $\begin{array}{l}\text { Up- } \\
\text { stream }\end{array}$ & $\begin{array}{l}\text { Down- } \\
\text { stream }\end{array}$ & & $\begin{array}{l}\text { Up- } \\
\text { stream }\end{array}$ & $\begin{array}{l}\text { Down- } \\
\text { stream }\end{array}$ & \\
\hline Monopoly & 56.36 & 9.02 & 25.01 & 4.00 & 94.39 & & & \\
\hline $\begin{array}{l}\text { End-to-End } \\
\text { Competition }\end{array}$ & 33.22 & 5.32 & 25.01 & 4.00 & 67.55 & 5.41 & 5.41 & 10.82 \\
\hline $\begin{array}{l}\text { Worksharing } \\
\text { without Bypass }\end{array}$ & 38.57 & 10.09 & 25.01 & 4.00 & 77.67 & 2.99 & & 2.99 \\
\hline $\begin{array}{l}\text { Worksharing } \\
\text { with Bypass }\end{array}$ & 33.22 & 5.32 & 25.01 & 4.00 & 67.55 & 5.41 & 5.41 & 10.82 \\
\hline
\end{tabular}

The case of worksharing with bypass equals the case of end-to-end competition. The reason is that the access price $\alpha$ is higher than the entrant's marginal delivery costs, i.e. $\alpha>\left(1-k_{E d}^{r}\right) c_{E d}^{r}$ for all $r$. As noted before, the entrant does not enter the rural region under end-to-end competition. Since entry into the rural region

12 It is however not ex post efficient. We refer to De Donder, Cremer and Rodriguez (2005) who discuss this point. 
is even more costly under worksharing without bypass than under end-to-end competition, the entrant never enters the rural region.

Under the assumptions made so far, in particular, under the assumption that the entrant's costs of innovation are the same as the incumbent's costs of innovation, it is no surprise that the strongest innovation incentives occur in the case of a regulated monopoly. Economies of scale are the underlying reason. Comparing different entry scenarios with multiple service providers, we can see that the incumbent's incentives to innovate are greater under worksharing without bypass than under end-to-end competition (or worksharing with bypass). This happens because the entrant is forced to set a higher price under worksharing without bypass than under end-to-end competition, since $\alpha>\left(1-k_{E d}^{r}\right) c_{E d}^{r} \forall r$. The incumbent's demand increases with an increase in the entrant's price, i.e. $\partial q_{I}^{r}\left(p_{I}, p_{E}^{r}\right) / \partial p_{E}^{r}>0$. Therefore, the incumbent's demand is higher under worksharing without bypass than under end-to-end competition, and investments in process innovations are more attractive. The entrant's innovation incentives are stronger under end-to-end competition (or worksharing with bypass) than under worksharing without bypass. One reason is that the entrant sets a lower price under end-to-end competition than in the other cases, as explained above. Thus, the entrant's demand is higher under end-to-end competition, and investments in process innovations are more attractive. Furthermore, the entrant only invests in optimizing its delivery process if operating in the downstream segment.

Table 2 shows the net effects of investments in innovation on profits by scenario.

In the monopoly case, we observe the greatest gains in profits. One reason is that as shown above, the incumbent's incentives to innovate are strongest in the monopoly case. The other reason is that the monopolist's investments in process innovation are exclusively added to the monopolist's profit, i.e., neither competitors nor consumers benefit.

When we compare the scenarios with multiple service providers, we see that the incumbent's added profits due to innovation are higher under worksharing without bypass than under end-to-end competition (or worksharing with bypass). One reason is that the incumbent invests more under worksharing without bypass. The other reason is that the incumbent benefits from the entrant's innovation activity only under worksharing without bypass. The incumbent benefits from the entrant's innovation because the entrant's process innovations result in lower marginal costs. Therefore, the entrant lowers its prices, and demand increases. Since the incumbent delivers the entrant's mail at an access price $\alpha$ per unit of mail, the entrant's payments to the incumbent increase.

Table 3 shows the net effects of investments in innovation on welfare. 
Table 2: Net Effects of Investments in Innovation on Profits by Scenario (Figures are in Millions of Euros)

\begin{tabular}{|c|c|c|c|c|}
\hline \multirow[t]{2}{*}{ Scenario } & \multicolumn{2}{|c|}{ Incumbent } & \multicolumn{2}{|c|}{ Entrant } \\
\hline & $\begin{array}{l}\text { Total } \\
\text { Investments by } \\
\text { the Incumbent }\end{array}$ & $\begin{array}{l}\text { Net Effect of } \\
\text { Investments on } \\
\text { Profits* }\end{array}$ & $\begin{array}{c}\text { Total } \\
\text { Investments by } \\
\text { the Entrant }\end{array}$ & $\begin{array}{l}\text { Net Effect of } \\
\text { Investments on } \\
\text { Profits* }\end{array}$ \\
\hline Monopoly & 94.39 & $\begin{array}{c}+94.39 \\
(94.87)\end{array}$ & & \\
\hline $\begin{array}{l}\text { End-to-End } \\
\text { Competition }\end{array}$ & 67.55 & $\begin{array}{l}+54.38 \\
(-47.06)\end{array}$ & 10.82 & $\begin{array}{l}+9.58 \\
(81.09)\end{array}$ \\
\hline $\begin{array}{l}\text { Worksharing } \\
\text { without Bypass }\end{array}$ & 77.67 & $\begin{array}{c}+77.82 \\
(80.75)\end{array}$ & 2.99 & $\begin{array}{l}+2.82 \\
(48.54)\end{array}$ \\
\hline $\begin{array}{l}\text { Worksharing } \\
\text { with Bypass }\end{array}$ & 67.55 & $\begin{array}{l}+54.38 \\
(-47.06)\end{array}$ & 10.82 & $\begin{array}{l}+9.58 \\
(81.09)\end{array}$ \\
\hline
\end{tabular}

* overall profit after innovation in brackets

Table 3: Net Effects of Investments in Innovation on Welfare by Scenario (Figures are in Millions of Euros)

\begin{tabular}{|c|c|c|c|c|}
\hline Scenario & $\begin{array}{l}\text { Total } \\
\text { Investments by } \\
\text { the Incumbent }\end{array}$ & $\begin{array}{l}\text { Net Effect of } \\
\text { Investments on } \\
\text { Profits* }\end{array}$ & $\begin{array}{l}\text { Net Effect of } \\
\text { Investments } \\
\text { on Consumer } \\
\text { Surplus** }\end{array}$ & $\begin{array}{c}\text { Net Effect of } \\
\text { Investments on } \\
\text { Social Surplus*** }\end{array}$ \\
\hline Monopoly & 94.39 & $\begin{array}{r}+94.39 \\
(94.40)\end{array}$ & $\begin{array}{c}+0.00 \\
(1501.20)\end{array}$ & $\begin{array}{c}+94.39 \\
(1596.10)\end{array}$ \\
\hline $\begin{array}{l}\text { End-to-End } \\
\text { Competition }\end{array}$ & 78.36 & $\begin{array}{c}+63.96 \\
(36.64)\end{array}$ & $\begin{array}{c}+10.19 \\
(1548.50)\end{array}$ & $\begin{array}{c}+74.15 \\
(1585.10)\end{array}$ \\
\hline $\begin{array}{l}\text { Worksharing } \\
\text { without Bypass }\end{array}$ & 80.66 & $\begin{array}{l}+80.64 \\
(130.03)\end{array}$ & $\begin{array}{c}+2.90 \\
(1527.40)\end{array}$ & $\begin{array}{c}+83.54 \\
(1657.40)\end{array}$ \\
\hline $\begin{array}{l}\text { Worksharing } \\
\text { with Bypass }\end{array}$ & 78.36 & $\begin{array}{r}+63.96 \\
(36.64)\end{array}$ & $\begin{array}{c}+10.19 \\
(1548.50)\end{array}$ & $\begin{array}{c}+74.15 \\
(1585.10)\end{array}$ \\
\hline
\end{tabular}

* overall profit after innovation in brackets

** overall consumer surplus after innovation in brackets

*** overall social surplus after innovation in brackets 
These results follow directly from the observed investments in innovation shown in Table 1. In a regulated monopoly consumers do not get any benefit from innovation, therefore the entire welfare gains go to the monopolist. In contrast, consumers do benefit from innovation whenever there are multiple service providers, although the service providers get the lion's share in all cases. It is important to note that although the difference in social surplus resulting from process innovation is highest in the monopoly case, the largest overall surplus results under worksharing without bypass. The main reason is that consumer surplus increases through product differentiation. Social surplus is higher under worksharing without bypass than under end-to-end competition because the incumbent's fixed costs to maintain its delivery network are divided over a larger quantity of mail.

We now introduce the possibility that the entrant can achieve the same cost reduction at lower investments than the incumbent. Formally, we write

$$
I_{E s}^{r}=\frac{1}{2} h z\left(k_{E s}^{r}\right)^{2}
$$

where $0<h<1$. By increasing the entrant's cost advantage, i.e., by decreasing parameter $h$, we get an idea of the robustness of our result that the added social surplus is highest in the monopoly case. Given our calibration, the entrant must be able to innovate at $33.2 \%$ of the incumbent's costs under end-to-end competition, and at $36.6 \%$ of the incumbent's costs under worksharing without bypass so that the scenarios with multiple service providers are more attractive than the monopoly case.

To evaluate the impact of a change in other critical parameters on our results, we perform sensitivity analyses. In particular, the access price $\alpha$ and the incumbent's uniform price $p_{I}$ deserve consideration. We subjected our results to variations of these parameters in the intervals $€ 0.40 \leq p_{I} \leq € 0.60$ and $€ 0.15 \leq \alpha \leq € 0.35$. We found that our main results are robust to variations in these intervals, i.e., the comparisons between different regulatory scenarios regarding investments into process innovations and welfare implications remain unchanged.

\section{Conclusion}

In general, a profit-maximizing monopolist has strong incentives to invest in process innovations. However, the monopolist's behaviour does not translate into added benefits for the consumers. Unless the entrant can innovate at no more than about a third of the incumbents' costs, the positive effects of process innovation on welfare decrease with liberalization. 
Although the incentives to invest in process innovations are strongest for a regulated monopoly, the largest overall surplus results under worksharing without bypass. Therefore, even though we find that the incentives to invest in process innovations decrease with liberalization; partial liberalization is desirable from an overall welfare point of view.

\section{References}

Arrow, K. (1962), "Economic Welfare and the Allocation of Resources for Invention" in: R. Nelson (ed.), The Rate and Direction of Inventive Activity, Princeton University Press, Princeton, NJ.

Baily, Martin N. and Hans Gersbach (1995), "Efficiency in Manufacturing and the Need for Global Competition", Brooking Paper on Economic Activity: Microeconomics, pp.307-358.

Blundell, Richard, Rachel Griffith and John Van Reenen (1995), "Dynamic Count Data Models of Technological Innovation", Economic Journal 105, pp.307-358.

Boone, Jan (2000), "Competitive Pressure: The Effects on Investment in Product and Process Innovation", RAND Journal of Economics 31/3, pp. 549-569.

Bradley, Michael D., Jeff Colvin and John C. Panzar (1997), "Issues in Measuring Incremental Cost in a Multi-Function Enterprise" in: Michael A. Crew and Paul R. Kleindorfer (eds), Managing Change in the Postal and Delivery Industries, Kluwer Academic Publishers, Boston, MA, pp. 3-21.

Braeutigam, Ronald and John Panzar (1989), "Diversification Incentives under Price-Based and Cost-Based Regulation", RAND Journal of Economics 20/3, pp. 373-391.

Cazals, Catherine, Marc De Rycke, Jean-Pierre Florens and Séverine Rouzard (1997), "Scale Economies and Natural Monopoly in the Postal Delivery: Comparison Between Parametric and Non Parametric Specifications" in: Michael A. Crew and Paul R. Kleindorfer (eds), Managing Change in the Postal and Delivery Industries, Kluwer Academic Publishers, Boston, MA, pp. 65-82.

Cazals, Catherine and Jean-Pierre Florens (2002), "Econometrics of Mail Demand: A Comparison between Cross-Section and Dynamic Data" in: Michael A. Crew and Paul R. Kleindorfer (eds), Postal and Delivery Services: Delivering on Competition, Kluwer Academic Publishers, Boston, MA, pp. 119-140. 
Cremer, Helmuth, André Grimaud, Jean-Pierre Florens, Sarah Marcy, Bernhard Roy and JoËlle Toledano (2001), "Entry and Competition in the Postal Market: Foundations for the Construction of Entry Scenarios", Journal of Regulatory Economics 19/2, pp. 107-121.

Crew, Michael A. and Paul R. Kleindorfer (1998), "Efficient Entry, Monopoly and the Universal Service Obligation in the Postal Sector", Journal of Regulatory Economics 14/2, pp. 103-126.

D’Aspremont, Claude and Alexis Jacquemin (1988), "Cooperative and Noncooperative R\&D in Duopoly with Spillovers", American Economic Review 78/5, pp. 1133-1137.

De Donder, Philippe, Helmuth Cremer, Jean-Pierre Florens, André Grimaud and Frank Rodriguez (2001), "Uniform Pricing and Postal Market Liberalization" in: Michael A. Crew and Paul R. Kleindorfer (eds), Future Directions in Postal Reform, Kluwer Academic Publishers, Boston, MA, pp. 141-163.

De Donder, Philippe, Helmuth Cremer and Frank Rodriguez (2005), "Access Pricing in the Postal Sector: Results from a Model with Bypass and Customer Direct Access" in: Michael A. Crew and Paul R. Kleindorfer (eds), Regulatory and Economic Challenges in the Postal and Delivery Sector, Kluwer Academic Publishers, Boston, MA, pp. 163-188.

De Villemeur, Etienne, Helmuth Cremer, Bernard Roy and Joëlle Toledano (2003), "Optimal Pricing and Price-Cap Regulation in the Postal Sector”, Journal of Regulatory Economics 24/1, pp. 49-62.

Dietl, Helmut, Urs Trinkner and Reto Bleisch (2005), "Liberalization and Regulation of the Swiss Letter Market" in: Michael A. Crew and Paul R. Kleindorfer (eds), Regulatory and Economic Challenges in the Postal and Delivery Sector, Kluwer Academic Publishers, Boston, MA, pp. 53-72.

Federal Council (2002), „Gesamtschau zur weiteren Entwicklung des Postwesens in der Schweiz - Bericht des Bundesrates und Botschaft über die Änderung des Postorganisationsgesetzes“, Available at http://www.admin.ch/ch/d/ ff/2002/5011.pdf.

Martin, Stephen (1993), "Endogenous Firm Efficiency in a Cournot PrincipalAgent Model”, Journal of Economic Theory 59, pp. 441-459.

Nickell, Stephen J. (1996), "Competition on Corporate Performance", Journal of Political Economy 104, pp.724-746.

Panzar, John (2002), "Reconciling Competition, Downstream Access, and Universal Service in Postal Markets" in: Michael A. Crew and Paul R. Kleindorfer (eds), Postal and Delivery Services: Delivering on Competition, Kluwer Academic Publishers, Boston, MA, pp. 93-115. 
Postal Rate Commission (2000), "Opinion and Recommended Decision", Docket No. R2000-1, Washington, DC.

PostReg (2005), „Tätigkeitsbericht 2005“, Available at http://www.postreg. admin.ch/imperia/md/content/postreg/berichte/10.pdf.

Postverordnung (2006), „Postverordnung vom 26. November 2003 (Stand am 10. Januar 2006)“, Available at: http://www.admin.ch/ch/d/sr/7/783.01. de.pdf.

Rogerson, Cathy M. and William M. Takis (1993), "Economies of Scale and Scope and Competition in the Postal Services" in: Michael A. Crew and Paul R. Kleindorfer (eds): Regulation and the Nature of Postal and Delivery Services, Kluwer Academic Publishers, Boston, MA, pp. 109-127.

Swiss Post (2003), "REMA Project - Alternative Methods of Implementation", Swiss Post, Politics and Post Report. Available at: http://www.swisspost.ch/ en/uk_rema_projekt.htm.

\section{SUMMARY}

We develop an industry specific model of price competition with product differentiation to analyze the effect of entry regulation on process innovation in the Swiss mail industry. We consider the four most prominent scenarios: Regulated monopoly, end-to-end competition, worksharing without bypass, and worksharing with bypass. Based on model calibration with data from the Swiss letter market, we find that the incentives to invest in process innovations decrease with deregulation. However, even accounting for this fact, the efficiency gains of a partial liberalization, i.e. worksharing, ensure an increase in social welfare. 